Portland State University

PDXScholar

1973

\title{
Self-awareness Testing for School of Social Work Students at Portland State University
}

\author{
Beverly Paull \\ Portland State University \\ Bette Schuman \\ Portland State University \\ Dorothy Davis \\ Portland State University
}

Follow this and additional works at: https://pdxscholar.library.pdx.edu/open_access_etds

Part of the Social Work Commons

Let us know how access to this document benefits you.

\section{Recommended Citation}

Paull, Beverly; Schuman, Bette; and Davis, Dorothy, "Self-awareness Testing for School of Social Work Students at Portland State University" (1973). Dissertations and Theses. Paper 1676.

https://doi.org/10.15760/etd.1675

This Thesis is brought to you for free and open access. It has been accepted for inclusion in Dissertations and Theses by an authorized administrator of PDXScholar. Please contact us if we can make this document more accessible: pdxscholar@pdx.edu. 
SELF-AWARENESS TESTING FOR SCHOOL OF SOCIAL WORK STUDENTS

AT

PORTLAND STATE UNIVERSITY

BEVERLY PAULL

BETTE SCHUMAN

DOROTHY DAVIS

A practicum submitted in partial fulfillment of the requirements

for the degree of

MASTER OF SOCIAL WORK

Portland State University

1973 


\section{TO THE OFFICE OF GRADUATE STUDIES:}

The members of the Committee approve the practicum of Beverly Paull, Bette Schuman and Dorothy Davis presented May 4, 1973.

APPROVED:

Gordon Hearn, Dean, School of Social Work 


\section{ACKNOWLEDGEMENT}

We wish to acknowledge and thank the following persons who contributed so much to this project: Dr. Tom Burgess, Director of Testing, Portland State University Counseling Center, who advised us about test selection and secured the cooperation of the Counseling Staff, whose comprehensive testinterpretation interviews with each student made this project possible; June Dunn, and Dr. Jack Hegrenes, Assistant Professors, Portland State University School of Social Work, who gave us guidance and encouragement.

Our special thanks are extended to the nineteen firstyear School of Social Work student subjects who cooperated in completing the two to three hour testing and test-interpretation experience.

We are especially indebted to the five students who gave us thoughtful comments about our pretest questionnaire. 
TABLE OF CONTENTS

Page

I. INTRODUCTION . . . . . . . . . . . 1

II. A REVIEW OF THE LITERATURE . . . . . . . 3

III. METHODOLOGY. . . . . . . . . . . 11

IV. FINDINGS ............. 18

V. CONCLUSIONS AND RECOMMENDATIONS. . . . . . 25

VI. BIBLIOGRAPHY . . . . . . . . . 32

APPENDIX A . . . . . . . . . . 35

APPENDIX B . . . . . . . . . . . . 36

APPENDIX C . . . . . . . . . . . . 37

APPENDIX D . . . . . . . . . . . 43

APPENDIX E . . . . . . . . . . . . 49 


\section{INTRODUCTION}

The purpose of this project was to evaluate from the student point of view the feasibility and desirability of self-awareness testing for first year School of Social Work students. Originally, the authors had hoped to arrange and evaluate mental well-being interviews for a significant sampling of students, using as a model the voluntary, private, completely confidential interviews that were conducted at McGill University's School of Social Work during 1961-1963. However, the task of funding offcampus professional interviews proved insurmountable. Therefore, the authors turned to objective personality testing with individual interpretive interviews conducted by counselors at Portland State University's Counseling Center.

Successful Social Work training depends upon the student's ability to develop and use his own personality as an instrument in the helping process. The student needs an opportunity to examine his own goals, values, needs, potentially useful and nonuseful aspects of his current self as he relates professionally to others.

An intrinsic part of self-growth is self-awareness. We recognize that opportunities for self-awareness are currently but not consistently available to the student via his field supervision, his interacting with other students and faculty, his use of encounter and other group experiences. We're suggesting that self-assessment testing for all first year students might be an additional method of enabling the student to heighten self-awareness. 
We are further suggesting that students can benefit from self-assessment testing because it may reveal personality traits that need to be strengthened if the students are to be effective in their roles as members of a helping profession. The test-interpretation experience should enable the student to see how he stands in relation to professionally desirable personality traits of warmth, empathy, genuineness, nonjudgmental attitudes and cognitive skills. The student whose test profiles indicated that he measured up adequately might experience greater self-acceptance and confidence. Revelation of deficiencies in these traits could motivate the beginning student to work toward improvement as part of his professional preparation. The test-interpretation experience should also give the student an opportunity to respond to a professional counselor in action and to possibly pick up some techniques for his own future use.

To our knowledge, no study at the School of Social Work has yet been designed to identify student perceptions of the amount and quality of self-awareness opportunities presently available. We are also seeking the student view of the importance of these opportunities in the school experience. 
A REVIEW OF THE LITERATURE

The Importance of Self-Awareness in Professional Education for Social Work

"Can one blind man lead another?

Will they both not fall into a pit?"

"Who are you who go about to save them that are lost?

Are you sound yourself?" Toward Democracy. Edward

Carpentier. London, 1921.

Charlotte Towle (1935), writing in what has become a classic statement concerning the mental hygiene of social workers, observed that self-ignorance has defeated many highly trained, well-informed, experienced caseworkers. Self-knowledge is basic in therapeutic interaction.

As we relate to others, the reaction we induce isn't merely the reaction of other individuals but is also the product of what we inject. The client reacts to the worker as an individual. A client may be free with one worker, constrained with another, amenable and hostile by turn with another. Since the worker determines the client's response, he cannot understand the client unless he understands himself. He must see himself in others and be aware of his own part in the client's response in order to see the client more nearly as he is.

An individual who doesn't know his own needs, biases, and blind spots is vulnerable when working in the field of mental health. A person in whom anxiety can be triggered or hostility aroused in 
certain kinds of interpersonal relations must, of necessity, be something other than completely neutral or objective when assessing his findings.

Wessel (1961) states that it has become almost axiomatic in social work education that the self of the student is at the very center of his learning; that changes in its use take place during the years of graduate study. The nature of that change is not clearly understood. It moves from the self-centeredness of the self-conscious learner to the generosity of reaching out to others in compassion.

Wessel believes that this change involves self-possession, a much deeper relation to one's own identity and inner resources than merely self-awareness. Heightened self-awareness is a first step in the student's finding himself in the profession in relation to its expectations, requirements and social values.

All aspects of student learning should result in the self of the student thriving through perceiving wider horizons and reaching beyond his present stature.

Boehm (1961), Towle (1961), and Wessel (1961) have focused upon facilitating in the student an openness to his own experiences. Their discussion emphasizes the student's personal development in the context of a therapeutic atmosphere calculated to cultivate essential self-knowledge which frees the student to become his most facilitative self. 
The Importance of Self-Awareness in the Helping Relationship

Jourard (1967) stresses the importance of self-awareness in noting that alienation from one's real self not only arrests personal growth but also tends to make a farce out of one's relations with people.

The effective social worker must have a firm sense of his own identity in dealing with maladjusted people. Jourard maintains that workers who themselves are anxious, immature or emotionally disturbed are far less effective in practise.

Macleod and Poland (1961) state that the individual who has a loosely delineated image of himself functions less effectively than a person with a clearer appreciation of himself, his roles and relationships, the value of his work and goals.

In discussing the therapeutic use of self, Watkins (1965) states that the good therapist is a product of much knowledge, of many learned techniques, of self-awareness and personal maturity. He learns to develop and utilize many aspects of his own being, not only intellectual but also emotional, social and behavioral.

What are the ingredients of this therapeutic self and how does one go about developing it in himself or in students? Watkins theorizes that it would seem necessary to have a genuine respect for the value and integrity of human life stuff, of each individual piece of it and an abiding desire to conserve and enhance it. Furthermore, he states that we need an ability to identify with others, to resonate to their hopes, aspirations, fears and angers. This ability to co-feel, co-sweat and co-suffer with another must be matched by a secure position of reality and maturity in the face of 
the other's neurotic strivings. If the practitioner identifies with the patient with his entire self, then a folie a deux is merely created. The two are sick together. Watkins believes that this therapeutic self is undoubtedly subject to growth and improvement. Janis et al (1969) define mature empathy as a process of temporary, controlled, partial identification. The practitioner's mature empathy presupposes a clear separation of self and other and a secure sense of identity. To be willing to let go of his own imnediate interests and to participate imaginatively in someone else's world, a person must have the security of knowing that he can slip comfortably back into his own skin. Capability in assessing others, therefore, requires that a person be aware of what goes on inside himself. He must be in touch with his own feelings and attitudes.

The research findings of Truax and Carkhuff (1967) indicate that counselors and therapists who offer high levels of accurate empathy, nonpossessive warmth and genuineness produce positive changes in their clients; therapists who offer low levels of these "therapeutic conditions" produce deterioration or no change in their clients.

In reviewing the findings of the behavioristic approaches to counseling and psychotherapy (Bandura, 1965; Eysenck, 1960; Krasner, 1962; Wolpe, 1965), Truax and Carkhuff note that the behaviorists have emphasized the fact that the therapist himself is a potent influencer of the patient's thinking and behavior.

The behaviorists have helped to put primary research focus on the personality, role and functioning of the therapist. 
There is a possibility that counselors high in empathy, warmth and genuineness are more effective in therapy because they're more personally potent positive reinforcers. Thus they elicit a high degree of positive affect in patients. This positive affect increases the level of the patient's positive self-reinforcement, decreases his anxiety and increases the level of positive affect in the patient and positive reinforcement from others.

It is also possible that therapists who are low in communicated accurate empathy, warmth and genuineness are ineffective and produce negative or deteriorating change in the patient. They are noxious stimuli who serve primarily as aversive reinforcers. Thus they elicit negative affect in the patient. The therapist himself serves as a model to be imitated as an example of effective human relating.

Rotter (1964) states that the self-understanding of the therapist is more crucial than any specific techniques he may employ. Luckey and Rich (1970) maintain that the key to counseling is the counselor himself. Counseling skill or art is no entity apart from the worker as a person--his training, attitudes, values, feelings. Knowledge of his own needs and the ways in which he seeks to fulfill them are as essential as his awareness of his social role with all of its expectations.

A great deal of knowledge of self is the prerequisite for the counselor's wise use of that self. The Use of Objective Testing to Increase Self-Awareness

Psychologists as a group appear to be dissimilar in their conception of how personality is to be measured. 
Allport (1961) states that there is no "one and only" method for diagnosing personality. Input from various sources--interviews, observation, interpersonal relations can enable an individual to heighten self-awareness.

Vernon (1964) defines an objective test as any test for which the method of scoring responses to the test materials is rigorously defined. Use of the word "objective" implies nothing about the nature of the test materials designed to elicit responses. It refers only to the method of scoring responses. The subject responds by checking pre-set answers which can be scored according to mechanical rules. The scores may then be subjected to various statistical manipulations which do not require any human judgment, subjective estimate, or the like. Janis et al (1969) have stated that since subjectivity always opens the door to bias and since it is not as constant in its operations as a machine, there are undeniable advantages to objective tests, at least in principle.

Self-report tests, then, are an additional approach to a person's conceptual system. Since the Personality Inventories cover many aspects of personality in a relatively short time, these instruments can be useful in personality research with subjects who are motivated to describe themselves as well as they can.

The validity of direct and undisguised self-report tests depends greatly upon the subject's honesty and self-knowledge since these tests are quite transparent and thus susceptible to the strategy of "faking good" and "faking bad," presenting yourself either as better or worse than you really are. 
The self-assessment process is closely connected with ambitions, ideals, levels of aspiration, as well as feelings of self-respect, inferiority, shame, guilt or pride. (Janis et al, 1969.)

Eysenck (1955) states that the conditions under which selfreport questionnaires are filled in, the intelligence and cooperativeness of the subjects, their insight and mood will powerfully affect or distort the results. Answers can never be taken at face value. He maintains that only when empirical relationships with other variables have been definitely established, under a reproducible set of conditions, will they take their place among other methods of investigation and throw important light on certain facets of the subject's personality (his own picture of himself, his insight, his desire to give a good account of himself), which would be difficult to obtain by any other method.

Eysenck concludes that questionnaires are a necessary but not sufficient means for arriving at a person's major traits and personality variables.

Vernon (1964) believes that skilled interviews may yield more reliable information, derived from less superficial layers of the self, but the inventory still possesses positive advantages. First, it can be readily normed or standardized, so that the person can be compared with others of his kind. The selector or counselor who prefers other approaches can evaluate the person's standing, or the strength of his attitudes only roughly and subjectively. Test scores, again, can be readily treated statistically, correlated with other variables or factorized. 
Secondly, self-report tests and inventories typically contain a considerable number of items which have been shown by item analysis to be relevant to the central concept or attitude; hence they tend to give a more reliable indication of this concept than a few random questions in an interview. For example, an adolescent's reply to a question on his vocational choice may reveal little because of his ignorance of the demands of the job; whereas the pattern of his answers to a large number of interest items gives a truer picture.

Thirdly, it might be maintained that some subjects, though not all, will be more candid and objective when answering an impersonal questionnaire than when interviewed or asked to write an autobiography.

The authors' object in the above discussion has not been to describe and evaluate self-report tests exhaustively, but to comment on conflicting opinions in the field of personality assessment. It would appear that self-report questionnaires do have a use.

We chose two representative examples of objective tests of personality traits in the psychometric tradition. These will be described in detail under Methodology. 


\section{METHODOLOGY}

\section{Sampling:}

The authors had originally hoped to test the entire first year School of Social Work class of 1972. However, the cost of the machine scoring for eighty students proved prohibitive. Therefore, we took a random sampling by picking the names of thirty students from a bowl in order to obtain a significant sampling for a descriptive study of self-assessment testing for School of Social Work students.

Out of the original randomly selected thirty students, we lost eleven, leaving us with a sampling of nineteen. These nineteen students cooperated fully with our testing, testing interpretation interview, and questionnaire experience.

of the eleven students we lost, one had dropped out of school, and one was ill, and although interested in our study was unable to participate in our testing. Three of the students indicated they were not interested in participating after receiving our initial letter; two were not interested in further participation after receiving the two personality tests; and two students said they lost the tests after we put them in their school boxes. One student did not understand our instructions and therefore did not follow through with the complete experience; and one student did not have enough time to complete the necessary interpretation interview. 


\section{Instrument:}

The task of selecting appropriate objective standardized tests that would fulfill our requirements at first seemed formidable due to our inexperience with testing. We needed instruments that were geared to our interest in self-awareness and that were also well tested, standardized, and validated. We were also limited to using testing instruments that were acceptable to the counselors at the Portland State University Counseling Center, as they had agreed to conduct the interpretive interviews.

The Adjective Check List was selected because it was short, easy to administer, and the counselors at the Counseling Center were familiar with it. It is generally considered to be an economical assessment of a normal population. Although easy to administer, its twenty-four scale profile produces a highly refined source of material for the interpretor-counselor.

According to Cottle and Downie (1960), this instrument by Harrison Gough $(1960,1965)$ is presented as a way of getting at the subject's self-concept. It is self-description and can be presumed valid unless there is reason to believe the subject is motivated not to reveal what he actually thinks of himself. The test consists of three hundred adjectives, and the instructions are: "Please put a check by each adjective that applies to you."

The Adjective Check List has been extensively used at the Institute for Personality Assessment and Research at the University of California where Gough developed it, and also elsewhere. It has proved empirically valuable in that independently defined groups of subjects differ in terms of the frequency with which their members 
check different adjectives. For example, results of one experiment singled out a group of subjects who were easily swayed by group influence, and another group who stuck to their guns despite the (manipulated) consensus of a group. The yielders significantly more often checked the adjectives optimistic, kind, obliging, patient, determined, and efficient. The uninfluenced subjects (at the same level of significance) described themselves as artistic, emotional, and original. These findings contributed to a meaningful picture of the self concepts of people who are not easily swayed by a group; a picture that fitted well with other data on their personalities.

According to Cottle and Downie, evidence points to the Adjective Check List as being a useful research instrument. It is simple, short, and nonthreatening.

The Omnibus Personality Inventory (Heist, 1962) was selected because it was especially designed to assess selected attitudes, values, and interests in areas of normal ego functioning and intellectual activities. Scales designed to assess ego functioning include social-emotional maturity, social concern, social relations, and self-confidence. However, these scales are not limited to measurement by single dimensions, but rather by scores on three or more scales.

Supplementary scales measured assessments of flexibility of general perception, degree of impulsivity, emotional disturbance, and anxiety. It was felt by the designers that a part of socialemotional adjustment was represented by a concern for the well-being of others. 
The Omnibus Personality Inventory (Buros, 1971) was originally developed as a special instrument to accommodate the research objectives at the Center for the Study of Higher Education, University of California at Berkeley. In 1958 a refinement and scale development process was initiated which eventually resulted in 1968 in the present Form F. version of the OPI.

Although originally designed to assess undergraduate student population within a variety of academic disciplines, it was felt by the authors to be adequate to revdal the qualities we were interested in within the postgraduate School of Social Work setting. The Omnibus Personality Inventory is geared toward viewing the individual as a changing, learning organism in the special social context of an academic institution. As such, the intellectual orientation and style of the individual is given strong emphasis. However, the maturity of the individual as seen in normal ego growth was also seen as important for success within the academic setting. In summary, the Adjective Check List and the Omnibus Personality Inventory were selected because of ease of administering, their relevancy to a normal student population, their well-tested validity and acceptability to the Counselors at the Counseling Center, and their ability to enhance self-awareness in sensitive areas that we considered most relevant to students of Social Work. We also reviewed the negative comments in the literature and decided the positive elements of the tests outweighed any drawbacks the tests might have. Procedure:

To enlist the cooperation of our student sample, we mailed an explanatory, invitational letter (see Appendix A) the week before the 
start of Winter term 1973. We also left duplicate letters in the thirty students' boxes at the School of Social Work in case the addresses were inaccurate.

Our letter stressed the opportunity to expand self-awareness in the interest of professional preparation, the strictly confidential handling of all materials, and our need for their cooperation in our Practicum Project. We gave them the option of attending two different group testing sessions at their convenience for administration of the standardized personality tests. We further explained that the tests would take about an hour and if this would be too inconvenient we would be willing to make other arrangements. It was pointed out that they, the students, were selected randomly, that all tests were to be machine scored, and that test results would not become part of our Practicum or part of their academic record. We also made it clear that the Portland State University Counseling Center would do all test interpretation directly to them and that our research material would be based on a follow-up questionnaire. (See Appendix D.)

We administered the tests ourselves at the School of Social Work in order to bypass the $\$ 7.50$ fee that the Counseling Center would charge for each student. Upon completion of their tests, the students were then given a written explanation of the procedure (see Appendix B) for calling the Counseling Center to arrange interpretation interviews. We made follow-up phone calls to those students who did not attend the test sessions. For those who still wished to cooperate, we arranged for them to pick up their testing material in their school boxes, complete the tests at home, and then return them to us. 
The completed tests were mailed to Interpretive Scoring Systems in Minneapolis, Minnesota, for machine scoring. We allowed two weeks for the results to be returned before the students were to schedule their interviews. We waited two more weeks and then made follow-up phone calls to those students who had not yet made appointments at the Counseling Center. We clarified our instructions and encouraged them to follow through. We were not able to contact two students and later learned that one did not understand our instructions and another did not have time to complete the project. Our post-interpretive interview questionnaire was designed around six points or areas:

1. The extent to which students felt opportunities for personal growth and self-understanding were available at the School of Social Work.

2. The usefulness of the testing and test-interpretation interview experience in facilitating self-awareness.

3. What factors made it a more or less useful experience.

4. If greater self-awareness led to more self-acceptance and confidence.

5. If students feel that the School of Social Work curriculum should incorporate such experiences or make them systematically available on an optional basis.

6. Whether Portland State University Counseling Center can appropriately fill this need and if more exposure to these counseling services would increase their use.

Our pretest questionnaire (see Appendix C) consisted of twenty-two questions with a request to comment on the clarity, redundancy, and any other useful thoughts after each question. 
We then selected five students from among our sample whom we knew had the time and interest in our Practicum to give us useful feedback. We selected two males and three females to avoid discrimination. We made it clear that we wished their cooperation in taking the final questionnaire later.

We then revised the original questionnaire, utilizing the suggestions contained within the returned pretest questionnaire and our original six points. Our final instrument consisted of twenty-one questions. Many of the questions had numerous parts and therefore the actual number of requested possible responses was forty-one, with seven opportunities for written comments.

The final questionnaire was then placed in the school boxes of all students in the sample who had made appointments at the Counseling Center. The questionnaire was carefully prefaced with an explanation and another reminder of confidentiality. We also asked for the student's name, age, sex, previous work experience in a helping profession, and length of time, and their area of professional interest. 


\section{FINDINGS}

A descriptive summary of questionnaire results follows. The findings are organized according to the six basic areas around which the questionnaire was designed, as described in the Methodology section. As in the questionnaire, the abbreviation $T / I$ experience will be used to refer to testing and test-interpretation experience. The tabulation of final responses is included in the Appendix on the questionnaire.

I. AVAILABILITY OF OPPORTUNITIES FOR PERSONAL GROWTH AND SELF-UNDERSTANDING AT THE SCHOOL OF SOCIAL WORK

Although all nineteen students who completed the final questionnaire felt that increasing self-awareness should be part of professional preparation, only nine said that the student can adequately seek out these experiences for himself within the school structure. The ten who felt that the student could not gave the following reasons:

1. There is too much school pressure; time and energy is therefore limited.

2. The school stresses academic and professional competence, does not advocate self-awareness or provide opportunities for it.

3. It depends on the student; some will, others will not. Responses indicated that field placements and other students offered a great deal of opportunity for personal growth, classes a moderate amount, and faculty advisors the least. 
II. USEFULNESS OF THE T/I EXPERIENCE IN FACILITATING SELF-AWARENESS

Thirteen respondents said they did learn something new about themselves as a result of the $T / I$ experience.

Students were asked how useful in gaining self-awareness this $\mathrm{T} / \mathrm{I}$ experience was in comparison with course content, field placement, faculty advisor, and other students. Table I shows the breakdown of responses.

TABLE I

COMPARISON OF T/I EXPERIENCE TO OTHER SCHOOL EXPERIENCES

The $T / I$ experience was:

more useful no difference less useful

\begin{tabular}{lccc} 
course content & 8 & 6 & 5 \\
\cline { 2 - 4 } field placement & 1 & 8 & 10 \\
\cline { 2 - 4 } faculty advisor & 10 & 5 & 4 \\
\cline { 2 - 4 } other students & 4 & 6 & 9 \\
\cline { 2 - 4 }
\end{tabular}

It is difficult, of course, to compare the testing and a one-hour interpretive interview with other experiences which have long-term continuity and commitment, such as field placement. The T/I experience would have to be of very high quality to have preference and points up the limitation of a one-time experience which is not an on-going, integral part of professional preparation.

Students were asked to assess the extent to which the T/I experience revealed their strengths and weaknesses in the interpersonal skills considered desirable for social workers. Strengths and weaknesses of which they were already aware were revealed to a high degree. The $\mathrm{T} / \mathrm{I}$ experience revealed strengths and weaknesses 
that the students were previously unaware of to a high degree for only two students. They were moderately revealed for three students and were brought out little or not at all for the remaining fourteen. In a separate question, all of the students indicated that the results were highly consistent with their self-concepts. These responses could indicate an already high degree of selfawareness among our subjects, but could also be a product of the limitations of self-report personality testing.

Twelve of the nineteen students reported having had previous personality testing, primarily in school. Eight of them felt that their previous testing was more useful. They gave the following reasons:

1. The previous testing had more impact because it provided new information; current test results were repetitive.

2. Students felt that they were now more self-aware.

3. Projective tests are more interesting.

4. They were exposed to the theory behind the earlier tests.

5. Previous testing was related to therapy. Although this $T / I$ experience had diminished value because of repetitiveness and brevity, previous testing appears to have been a meaningful tool towards self-understanding for these students. Self-awareness should enable the social worker to recognize when identification, projection, and biases occur in his professional role. In a question intended to assess whether the $T / I$ experience had aided the student in this respect, only two students answered "Yes," but twelve felt that although it hadn't done so yet, it may in the future. 
A breakdown of the respondents' overall reactions to the experience shows that:

$\underline{\text { Reaction }}$

1. Waste of time

2. Interesting, but not personally helpful

3. Both 1 and 2

4. Personally helpful

5. Professionally useful

6. Both 4 and 5
Number

1

2

1

7

1

7

III. FACTORS WHICH MAKE THE T/I EXPERIENCE MORE OR LESS USEFUL

The factors which made it a more or less useful experience appear in the reasons students gave for the above reactions. Those who said it was a waste of time said it was not helpful. Students who found it interesting but not personally helpful said they did not learn anything new and that the results correlated with previous testing. Reasons given for finding it personally helpful were:

1. It confirmed and reinforced their self-concept and awareness.

2. It reinforced personal goals.

3. It was another way of understanding oneself.

4. It facilitated personal and directional change.

5. It was an avenue to counseling.

Those who found it professionally useful said:

1. They learned about testing and appreciate its value.

2. Professional self-awareness is desirable.

3. They became aware of personal biases and propensities.

4. The counselor discussed the professional implications of the test results. 
5. Being in the client role increased their empathic ability.

The thirteen students who said they learned something new about themselves were asked how this affected four areas of functioning. Table II shows their responses.

\section{TABLE II}

EFFECTS OF NEW LEARNING ON FUNCTIONING

\begin{tabular}{|c|c|c|c|}
\hline & positively & same & negatively \\
\hline personal relationships & 4 & 9 & 0 \\
\hline functioning at school & 3 & 10 & 0 \\
\hline functioning in the field & 5 & 8 & 0 \\
\hline attitude toward self & 10 & 3 & 0 \\
\hline other (specify) & 2 & 0 & 0 \\
\hline
\end{tabular}

Twelve students reported a positive change in at least one of the above areas. The "other" positive changes noted were a willingness to participate in counseling and a change in professional direction. of those who said the experience had no effect in these areas, six anticipate future changes as a result.

All of the students felt well received and comfortable with their counselors during the interpretive interview. Eighteen of the students trusted the confidentiality of the project; one did not at first, but did as the interview progressed.

Seven students said they picked up useful techniques for their own use during the interpretive interview. Examples given were learning how to deal effectively with anger and learning how to relax.

The questionnaire provides some data which distinguish the four students for whom the $T / I$ experience was not useful. Although the test results were consistent with their self-concepts, they learned 
nothing new about themselves. Only one of the four had had previous personality testing; eleven of the fifteen subjects who found it a useful experience had had prior testing. Average number of years' experience in a helping profession is 2.1 for these four students, as compared with 3.3 years for the remaining fifteen. However, the questionnaire did not provide enough information to enable supportable inferences to be drawn.

IV. RELATIONSHIP OF SELF-AWARENESS TO SELF-ACCEPTANCE AND CONFIDENCE

The responses indicate that the experience was personally reinforcing to many students by reaffirming their self-concepts and thereby diminishing anxiety. Eight of the students who said that the experience was "personally helpful" gave this as the reason. Although this was not the primary objective of the project, it is certainly a valuable fringe benefit, considering the academic and professional pressures students operate under. Other responses which support this effect are:

1. Six students reported that the experience diminished anxiety.

2. The test results were highly consistent with all of the subjects' self-concepts.

3. Ten said that the experience positively affected their attitude toward self.

4. Eight felt more positive about choosing social work as a profession as a result of the experience.

5. The tests revealed strengths and weaknesses they were already aware of more than those of which they were unaware.

6. Test results were consistent with results of previous personality testing. 


\section{DESIRABILITY OF THE T/I EXPERIENCE AS PART OF THE SSW CURRICULUM}

Students were not generally in favor of paying the $\$ 7.50$ Counseling Center fee for testing and interpretation ( 5 Yes, 13 No, although the questionnaire explained that the usual Counseling Center procedure was to conduct a pretest interview and select appropriate tests for each individual student. However, nine students felt that it should be part of the SSW experience. Of those who answered No, four qualified their responses by saying they would favor it if optional or free. If offered on an optional basis, then, thirteen students would apparently support such a program. It was interesting to note that of these thirteen students, nine had had previous personality testing.

Students who did not feel that it should be part of the SSW experience gave the following reasons:

1. It has no benefit.

2. Its usefulness depends on how aware the student already is.

3. Counseling is more useful.

4. A course on testing would be more beneficial than a one-time experience such as this.

VI. USE OF THE PSU COUNSELING CENTER TO FACILITATE PERSONAL GROWTH AND SELF-AWARENESS

Information was gained regarding the feasibility of using the Counseling Center as a resource for personal growth and self-awareness. We hypothesized that greater use of this facility should result from a positive experience during this project. Thirteen subjects were already aware of Counseling Center services; six were not. Nine said they were now more likely to use the Counseling Center, primarily for individual counseling. Three students have planned follow-up contacts. 


\section{CONCLUSIONS AND RECOMMENDATIONS}

Student evaluations of this project support the authors' contentions that enhancing self-awareness is an important aspect of professional preparation, that opportunities for this are not systematically available at the School of Social Work, and that a structured experience consisting of personality testing and interpretive interviews is a viable adjunct to presently available experiences.

As previously noted, fifteen of the nineteen students who completed this project found the T/I experience personally helpful and/or professionally useful. In terms of the original student sample of thirty, fifty per cent found it to be a valuable experience. Part of the sample loss can be accounted for by straightforward reasons, such as being ill or too busy. other students who dropped out of the project because of losing the tests, misinterpreting instructions or "not wishing to learn more about themselves" may have found the experience too threatening. With this line of reasoning we might also speculate that those who completed the project may be a more secure group of students who are interested in new self-awareness.

From our student sample's point of view, the school program presently does not give enough recognition to the importance of heightening student self-awareness as part of professional preparation. Although they believe that field-placement experiences and interaction with other students definitely heighten self-awareness, over half of the student respondents felt that they could not adequately seek out other self-awareness experiences. It is apparent that the faculty adviser system is not used for this purpose. They concurred with our belief that the developing student definitely 
needs more opportunities to examine the potentially useful and non-useful aspects of his current self. Factors limiting selfexamination are: academic pressure, which limits time and energy; insufficient opportunities provided by the school; and the school's emphasis on academic and professional competence.

The authors had anticipated that the value of the $T / I$ experience to the students would be a product of increased selfawareness in areas relevant to professional functioning. This does not appear to be the case. Although thirteen students reported learning something new about themselves, the testing and interpretive interview revealed personal qualities they were already aware of much more effectively than qualities of which they were previously unaware.

The primary value appeared instead to hinge on an unexpected side-effect of the interpretive interviews: they proved to be highly reinforcing for over half of the respondents. The opportunity to assess their own test profiles in terms of professionally desirable personality traits and to discuss their own self-concepts in a confidential, nonthreatening atmosphere seems to have had the "inspiriting"1 effect of enhancing self-awareness and self-confidence. The authors also noted this "inspiriting" effect from their own interpretive interviews; further description of the authors' experiences is contained in Appendix E. It is interesting to note that this effect correlated with the findings of the well-being interviews conducted at McGill University, which originally inspired this project.

\footnotetext{
1"Inspiriting" is a term coined by Jourard (1967) which refers to a general state of heightened enthusiasm and morale.
} 
The personally reinforcing aspect of this experience is especially noteworthy in view of the anxiety often experienced by first-year social work students. A prior study at the School of Social Work shows that the level of anxiety among first-year students is extremely high. According to Luft (1963), this can interfere with the learning process. He states that too much tension depresses learning because the individual may have difficulty organizing his experiences since he is too busy trying to survive psychologocally.

Secondary gains for the participants in this project involved the opportunity to observe a trained counselor in action from the client point of view, as compared with student observation; this seems to have merit for picking up new techniques and heightening empathic abilities.

We assumed that the majority of students had not had previous personality testing and that the experience would be more useful for those who had not. Our findings, however, show that twelve had undergone previous testing, and although eight of these reported that their previous testing had more impact, seven of the eight still considered this $T / I$ experience valuable. We might infer that these seven students approached the experience with a positive attitude regarding the value of testing and that the interpretive interview provided an additional and perhaps the most valuable dimension.

This raises the possibility that the primary impact and value of the experience was due more to the interpretive interview than to the test results. Only three students made explicit reference to the testing aspect when discussing reasons why they found 
the experience beneficial. Since the questionnaire did not explore this point, we can only speculate as to whether the testing or interview was the more determining factor or whether the interview alone would have been sufficient. The test results did furnish both counselor and student with a large amount of information, which could not have been elicited or dealt with in one or two interviews. But just how much of this wide range or information was of interest or use to the student is open to question; one or two points carefully explored may have been of more value. Determining feasibility of a T/I experience for social work students depends on finding an appropriate, accessible and effective resource for conducting such a project. The PSU Counseling Center appears to meet all these criteria. Counseling, on an individual or group basis, is available to all PSU students free of charge. Although a flat $\$ 7.50$ fee for testing is charged, there is no limit to the number or type of tests a student may take. Further, the Counseling Center is experienced in dealing with students and student problems. Our respondents' unanimous replies that they felt comfortable about confidentiality and willing to reveal themselves support our view that the Counseling Center offers a confidential and nonthreatening atmosphere in which to deal with personal issues. Only six of our nineteen subjects were not previously aware of the Center services. However, after the T/I experience, nine said they were now more likely to use the Center and three are currently engaged in counseling there. These responses indicate that exposure to services there will increase this resource's use by social work students. 
Student responses to this project brought to our attention several limitations in its design. A primary weakness was the use of pre-selected, standardized tests, which were repetitive for some students and of minimal personal relevance for others. The brevity of the experience also reduced its maximum impact; it was a relatively small part of the total school experience. The effectiveness of self-report testing in revealing personality traits beyond an idealized self-concept also depends on the subject's willingness to explore and reveal himself honestly.

These limitations would be eliminated if the students were willing to pay the $\$ 7.50$ Counseling Center fee for its individualized testing service. This procedure includes an initial interview to determine appropriate testing for the individual student and interpretive follow-up interviews.

The importance of this procedure is elucidated by Janis et al (1969) who believe that objective assessment can learn from the clinical tradition. They contend that there is no bypassing judgment; in an objective test, the examiner relies on the subject to observe and report on his own behavioral patterns. Objective measurement will be advanced, therefore, when the subject is helped to do as good a job as possible. That can be accomplished first, by earning his trust and confidence so that his defensiveness will be minimal. This means not trying to trick the subject or pry into his inner life without his consent; it means respecting his confidence meticulously and being completely candid about how the results are used. Taking the test seriously and reporting accurately, then, will be enhanced by establishing a prior relationship between 
interpreter and subject. They conclude that there is no escape from the necessity of interpreting the results of any test.

Since the findings of this project indicate that from the students' point of view the T/I experience is both a desirable and feasible part of social work training, the authors recommend that first-year social work students undergo, on a voluntary basis, the routine Counseling Center testing procedure, as described above. We recognize that funding for this would be a problem. Our student sample was generally unwilling to pay for this and because of the current fiscal crisis, the School of Social Work does not have available funds for such purposes. We recommend that the school reassess its commitment to this aspect of professional preparation and explore the possibility of an NIMH training grant for this purpose. Alternatively, the school could encourage students to pay the fee themselves by actively promoting the PSU Counseling Center as a resource to facilitate professional self-awareness. The Admissions Committee or the Orientation Committee would be appropriate for this.

Our second recommendation is less desirable, but financially more realistic: The School of Social Work could offer optional, standardized testing, with the $\$ 2.00 \mathrm{fee}^{1}$ paid by the student and the Counseling Center doing interpretive interviews, as in this project. We envision the school's role to be one of publicizing the $\mathrm{T} / \mathrm{I}$ opportunity via methods classes or discussion in the large core course. Second-year students could conduct the testing sessions if faculty time is too limited.

1The $\$ 2.00$ fee per student covered the cost of test materials and machine scoring in this project. 
Our third recommendation is that a course in testing be made available to social work students in which the students themselves would be the subjects. This would allow the student time to compare and integrate findings, as well as to understand the theoretical bases of the tests and their limitations for future professional use.

In conclusion, our recommendations suggest that the School of Social Work should provide additional avenues for students to develop personal and professional self-knowledge. It is hoped that this study is a preliminary step towards the planful incorporation of such experiences into the School of Social Work program. 


\section{BIBLIOGRAPHY}

Arbuckle, D. S. "Client Perception of Counselor Personality." J. Con. Psychol. 1956, 3, pp. 93-97.

Bandura, A. "Psychotherapist's Anxiety Level, Self-Insight, and Therapeutic Competence." J. Abnor. Soc. Psy. 1956, 52, pp. 333-38.

Biestek, F. P. The Casework Relationship. Chicago, Loyola University Press, 1957.

Boehm, W. "Social Work: Science \& Art." Soc. Ser. Review. 1961, 35, pp. 144-51.

Buros, 0. K. Mental Measurement Yearbooks. Evaluation of Tests. 1971.

Cottle, C., Downie, N. Procedures and Preparation for Counseling. Prentice-Ha11, N. J., 1960.

Diggory, J. Self-Evaluation Concepts \& Studies. Random House, N. Y., 1966 .

Edwards, A. Measurement of Personality Traits by Scales \& Inventories. Houghton, Mifflin Co., N. Y., 1970.

Eysenck, H. G. The Structure of Human Personality. Barnes \& Noble, London, 1955.

Gough, H., Ph.D., Heilbrun, A., Ph.D. The Adjective Checklist Manual. Consulting Psychologist Press, Palo Alto, California, 1965.

Heist, P., Young, G. Omnibus Personality. Inventory Manual, Form F. Psychological Corp., NYC, 1962, 1968.

Hollis, F. Casework: A Psychosocial Therapy. Random House, N. Y., 1964 .

Holt, R. Assessing Personality. Harcourt, Brace Company, N. Y., 1971.

Janis, I., Mahl, G., Kagan, J., Holt, R. Personality: Dynamics, Development, and Assessment. Harcourt, Brace Company, N. Y., 1969.

Jourard, S. The Transparent Self. Reinhold Co., N. Y., 1964. 
Lanyon, R. Personality Assessment. World Press, N. Y., 1971.

Luft, J. Group Process: An Introduction to Group Dynamics. National Press Books, Palo Alto, California, 1963.

MacLeod, A., M.D., Poland, P., Silverman, B. "The Well-Being Clinic. A Study of the Effectiveness of an Attempt to Provide Routine Mental Health Check-ups for Community Groups." American J. Psychiatry, Vol. 113, No. 9, March, 1957.

MacLeod, A., M.D., Poland, P. "The Well-Being Clinic." Social Work, Jan. 1961, pp. 13-18.

McGowan, R., Schmidt, S. Counseling: Readings in Theory \& Practise. Holt, Rinehart Co., 1962 .

Mensh, I., Research in Counseling and Psychotherapy. Vo1. II. D. Brower, L. Abt, Eds. N. Y., 1956.

Mische1, W. Personality Assessment. Wiley \& Sons, N. Y., 1968.

Moustakas, C. The Self: Explorations in Personal Growth. Harper Bros., N. Y., 1956.

Newe11, A. Contemporary Thought in Guidance and Counseling. Harpers, N. Y., 1972 .

Perlman, H. Social Casework: A Problem-Solving Process. U. of Chicago Press, Chicago, 1957.

Raimy, V., Self-Concept in Counseling and Personality Organization. McGraw-Hil1, 1971.

Rogers, C., On Becoming A Person. H. Mifflin, Boston, 1961.

Rotter, J. Clinical Psychology. Prentice-Hall, N. J., 1964.

Seltig, C. Research Methods in Social Relations. Revised Ed. Holt-Rinehart, N. Y., 1965.

Semmons, J. \& Krantz, K. The Adolescent Experience. Macmillan Co., N. Y., 1970.

Simon, J. Research Methods in Social Science. Random House, N. Y., 1969 .

Strecker, E., \& Appel, K. Discovering Ourselves. Macmillan Co., N. Y., 1963.

Towle, C. Mental Hygiene of Social Workers. Illinois Conference on Social Work, 1935. 
Truax, C. \& Karkhuff, R. Toward Effective Counseling \& Psychotherapy, Aldine Co., N. J., 1967.

Tyler, L. The Work of The Counselor. Appleton Co., N. Y., 1969.

Vernon, P. Personality Assessment. Butler \& Tanner, Ltd., London, 1964.

Walton, H. "Personality Correlates of a Career Interest in Psychiatry." Brit. J. Psy. 115 (519), Feb., 1969.

Watts, A. Theory of Self-Knowledge. Assoc. Press, N. Y., 1953.

Wessel, R. "Social Work Education \& Practise." Soc. Service Review, 1961, 35, pp. 151-60.

Wolman, B. Handbook of Clinical Psychology. McGraw-Hill, Article, "Therapeutic Methods," J. Watkins, Ph.D. p. 1152.

Wyatt, F. "The Self-Experience of the Psychotherapist." J. Consult. Psychol. 12, pp. 83-89.

Wylie, J. The Self-Concept. Random House, N. Y., 1961.

Zerfoss, C. Readings in Counseling. Assoc. Press, N. Y., 1953. 
APPENDIX A

December 28, 1972

\section{Dear Fellow Students:}

We are inviting your participation in a Practicum Project designed to determine from the student's point of view, the desirability of self awareness testing for SSW students. We hope that you will participate in the project for two reasons. First, this is a pilot project and we need your help! Second, our objective is to give you an opportunity to expand your self understanding and to find out whether interpretation of your test results is of interest and value to you as part of your professional preparation.

A group of thirty first year students is being asked to take two standardized personality tests. Your name was selected by random sampling. The tests will be machine scored. Results will be interpreted in individual interviews at the PSU Counseling Center. These results are strictly confidential and are for your personal use only. We wish to emphasize that this information will not become part of your academic record or our Practicum record.

Tests will be given on two different dates at the School of Social Work and will take about an hour. Please plan to attend whichever session is most convenient for you. Friday, January 5 th at 1:15; or Tuesday, January 9 th at 3:15 in room 106 in SWI.

If you cannot come on either of these dates, please call one of us immediately and we will make other arrangements.

In order to validate our Practicum it is most important that you return the post interview questionnaire that will be mailed to you in February.

Thank you for your cooperation. We hope to see you next week.

$$
\begin{array}{lc}
\text { Bev Paull } & 639-3528 \\
\text { Dorie Davis } & 281-4135 \\
\text { Bette Schuman } & 645-2139 \\
\multicolumn{2}{c}{\text { Second year SSW Students }}
\end{array}
$$




\section{APPENDIX B}

Please call the counseling center immediately, 229-4423, and make an appointment for test interpretation. To allow time for tests to be scored and returned, the appointment should be scheduled for as soon as possible after January 23rd. When you call, identify yourself as participants in the SSW Practicum project. 
APPENDIX C

This is a pretest questionnaire to evaluate our final questionnaire. Only five students have been selected to take the test. You will still be asked to take the final test later. Please comment on each question as to clarity of meaning, redundancy, or any other thoughts you might have pro or con. Thank you. NAME AGE_ MALE_ _ FEMALE PREVIOUS WORK EXPERIENCE

AREA OF PROFESSIONAL INTEREST (C.O., DIRECT SERVICE, ETC.)

1. Interpersonal skills (warmth, genuineness, empathy, non-judgmental attitude, cognitive skills, etc.) are considered desirable personal qualities for social workers.

A. How much did the testing reveal strengths you were already aware of? greatly_, somewhat_, none

B. How much did the testing reveal strengths you were not aware of? greatly _, somewhat, none

C. How much did the testing reveal weaknesses you were already aware of? greatly_, somewhat_, non

D. How much did the testing reveal weaknesses you were not aware of? greatly___, somewhat___, none__.

Comment on question please.

2. In regard to your feeling of suitableness for the SW profession, this experience:

heightened anxiety diminished anxiety , didn't affect anxiety am not anxious 
Comment on question please.

3. Did you feel that your test profiles were consistent with your own self concept? (By this we mean how you see yourself and how you feel about yourself.)

very much , somewhat , very little , not at al1

Comment on question please.

4. Did you learn anything new about yourself? yes , no not sure

If yes, how has this affected your:

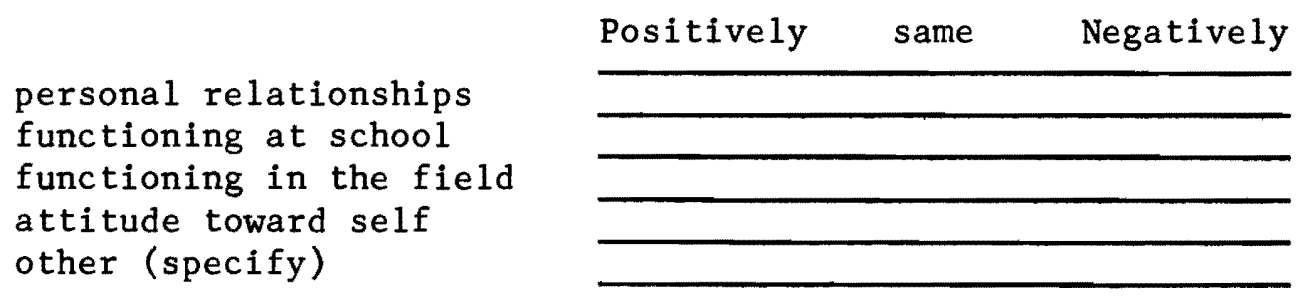

Comment on question please.

5. Has increased self awareness through this experience enabled you to be more objective with clients by recognizing when identification, projection, or biases occur?

yes__, no __, not yet___, but may__, N.A. ___ Comment on question please.

6. To what extent do the following areas provide opportunities for personal growth and self understanding? 
classes

field placement

other students

faculty advisor

other (specify)

Please comment on question.

7. In comparing this testing experience with the following experiences

at school, this testing experience was:

$$
\text { more useful less useful no difference }
$$

course content

field placement

faculty advisor

other students

Comment on question please.

8. Do you feel that increasing self understanding should be an important part of professional preparation? yes , no

Comment on question please.

9. Do you feel that the student can within the school structure adequately seek out these experiences for himself? yes , no

If not why not?

Comment on question please.

10. Have you previously had personality or self awareness testing?

yes__ no n__

If yes, where? school__ job___, private__, other (specify)__

Comment on question please. 
11. Was your previous testing experience more useful to you than this experience? yes__ no___ If yes, why?

Comment on question please.

12. The PSU Counseling Center offers individualized testing with

a pretest interview and an interpretive post-interview for $\$ 7.50$.

A. Would you be willing to pay for this service? yes, no

B. Do you think SSW students should be expected to do this as part of their school experience? yes If no, why not?

Comment on question please.

13. Did you feel "well received" and comfortable with your counselor during the interpretive interview? yes_, no ___. If no, why not?

Comment on question please.

14. What was your overall reaction to the test-interpretation experience?

A. Waste of time___. If so, why?

B. Interesting but not personally helpful If so, why? 
C. Personally helpful___. If so, how?

D. Professionally useful___. If so, how?

Comment on question please.

15. If not personally helpful, do you feel that there are students for whom it would be? yes , no

Comment on question please.

16. Did you feel comfortable about confidentiality? yes_, no___ Comment on question please.

17. Did you feel safe to reveal yourself? yes_, no ___ Comment on question please.

18. Were you previously aware of the services available at the PSU Counseling Center? yes_, no ___ Comment on question please.

19. Are you now more likely to use the PSU Counseling Center Services? yes , no 
If yes, which: testing

individual counseling

group experience

other

Comment on question please.

20. Are you planning any follow-up contacts at the Counseling

Center? yes __ no ___.

Comment on question please.

21. Did the opportunity to see a professional interviewer in action change your attitude toward the usefulness of counseling? yes

no

If yes, how?

Comment on question please.

22. Did you pick up any useful techniques for your own use? yes

no

Please comment on question. 


\section{APPENDIX D}

The tabulation of responses on each question has been recorded on this questionnaire.

This is a follow-up questionnaire to evaluate the usefulness of the testing and testing interpretation experience that you participated in for our Practicum Project. Let us remind you again of the stress we have placed on confidentiality. Please complete this questionnaire by March 7 th and return to Bev Paull's box.

Again let us thank you very much for your cooperation. Bev Paul1, Bette Schuman, Dorie Davis

NAME 19 students

AGE $23-48$ MALE 8 FEMALE 11

PREVIOUS WORK EXPERIENCE IN A HELPING PROFESSION 16 in a helping profession, 3 no experience LENGTH OF TIME_Average of 3 yrs. AREA OF PROFESSIONAL INTEREST (C.0., DIRECT SERVICE, etc.) 13 direct service; 1 C.0.; 1 health systems; 1 C.0. \& Direct Service; 2 direct service \& facilitative; \& 1 no answer.

Throughout this questionnaire, "T/I experience" will be used as an abbreviation for the testing and testing interpretation experience. 
1. Interpersonal skills (warmth, genuineness, empathy, nonjudgmental attitude, cognitive skills, etc.) are considered desirable personal qualities for social workers. Circle the most appropriate number on the scale.

A. How much did the $T / I$ experience reveal strengths you were already aware of?

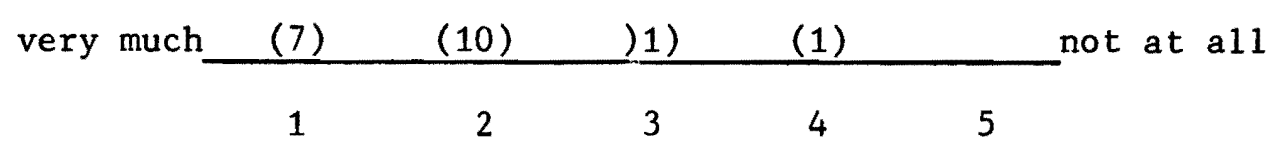

B. How much did the $T / I$ experience reveal strengths you were not aware of?

very much $\begin{array}{lllll} & (2) & (3) & (11) & \text { (3) } \\ 1 & 2 & 3 & 4 & 5\end{array}$ not at a11

C. How much did the $T / I$ experience reveal weaknesses you were already aware of?

\begin{tabular}{|c|c|c|c|c|c|}
\hline very much & (4) & $(9)$ & $(4)$ & $(2)$ & not at all \\
\hline & 1 & 2 & 3 & 4 & \\
\hline
\end{tabular}

D. How much did the $T / I$ experience reveal weaknesses you were not aware of?

very much $\begin{array}{ccccc}(1) & (1) & (3) & (7) & (7) \\ 1 & 2 & 3 & 4 & 5\end{array}$

2. In regard to your feeling of your suitability for the SW profession, this $\mathrm{T} / \mathrm{I}$ experience:

heightened anxiety (1), diminished anxiety (6), didn't affect anxiety (9), am not anxious (3).

3. How did the $T / I$ experience make you feel about choosing $S W$ as a profession? more positive (8), no differently (10), less positive (1). 
4. Did you feel that your test profiles were consistent with your own self concept? (By this we mean how you see yourself and how you feel about yourself.)

very much $(10)$ not at all

$\begin{array}{lllll}1 & 2 & 3 & 4 & 5\end{array}$

5. Did you learn anything new about yourself? yes (13), no (6), not sure

A. If yes, how has this affected your:

\begin{tabular}{|c|c|c|}
\hline Positively & same & negatively \\
\hline (4) & (9) & \\
\hline (3) & (10) & \\
\hline (5) & $(8)$ & \\
\hline (10) & (3) & \\
\hline (2) & & \\
\hline
\end{tabular}

B. If you checked "same" in any category, do you anticipate any future changes as a result of the $t / I$ experience? yes (6), no (5), maybe (2).

6. If the $T / I$ experience has increased self awareness has it enabled you to be more objective with clients by recognizing when identification, projection, or biases occur?

Yes (2), No (1), Not yet but may (12), not applicable (3).

7. To what extent do the following areas provide opportunities for personal growth and self understanding?

classes:

very much $\begin{array}{lllll}(1) & (4) & (6) & (7) & (1) \\ 1 & 2 & 3 & 4 & 5\end{array}$


field placement:

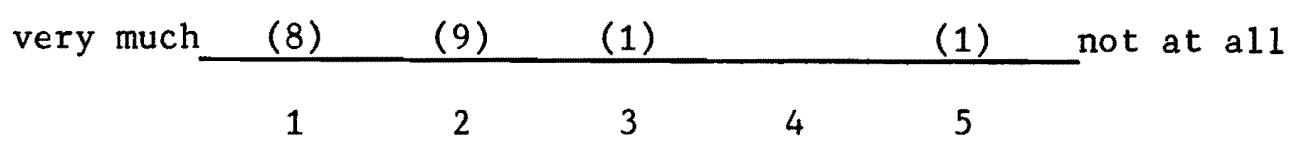

other students:

very much (7)

(8) (3)

not at all

$\begin{array}{lllll}1 & 2 & 3 & 4 & 5\end{array}$

faculty advisor:

very much

(2)

(5)

(3)

(9) not at all

1

2

3

4

5

other (specify):

very much

(1) not at all

1

2

3

4

5

8. In comparing this $T / I$ experience with the following experiences at school in terms of self awareness, this $T / I$ experience was: more useful no difference less useful

course content (8)

(6)

field placement

faculty advisor

(8) (10)

\begin{tabular}{ccc}
$(1)$ & $(8)$ & $(10)$ \\
\hline$(10)$ & $(5)$ & $(4)$ \\
\hline$(4)$ & $(6)$ & $(9)$ \\
\hline
\end{tabular}

other students

9. Do you feel that increasing self awareness should be an important part of professional preparation? yes (19), No

10. Do you feel that the student can within the School of Social Work structure adequately seek out self awareness experiences for himself? yes (9), no (9). I don't know.

If not, why not?

11. Have you previously had personality testing? yes (12), no (7). A. If yes, where? school (12), job (4), private (3), other (specify) 
B. If yes, was your previous testing experience more useful to you than this experience? yes (8), no (5). If yes, why? 12. In contrast to this $\mathrm{T} / \mathrm{I}$ experience, the PSU Counseling Center routinely offers a pretest interview to determine tests which would be most useful for the individual student, and an interpretive post interview for $\$ 7.50$.

A. Would you be willing to pay for this service? yes (5), no $(13)$.

B. Do you think SSW students should be expected to do this as part of their school experience? yes (9), no (7). If no, why not?

13. Did you feel "well received" and comfortable with your counselor during the interpretive interview? yes_(19), no___. If no, why not?

14. What was your overall reaction to the $T / I$ experience?

A. Waste of time (2). If so, why?

B. Interesting but not personally helpful (3). If so, why?

C. Personally helpful (14). If so, why?

D. Professionally useful (8). If so, why?

15. Did you feel comfortable about confidentiality within this $T / I$ experience? yes (18), No

16. Did you feel willing to reveal yourself? yes (19), no (1).

17. Were you previously aware of the services available at the PSU Counseling Center? yes (13), no (6). 
18. Are you now more likely to use the PSU Counseling Center

Services? yes (9), no (10).

If yes, which:

testing (2), individual counseling (7), group experience (3),

other

19. Are you planning any follow-up contacts at the Counseling

Center? yes (3), no (16).

20. During the interpretive interview, did you pick up any new

techniques for your own use? yes (7), no (12).

21. Any further comments? 
APPENDIX E

The authors also participated in the entire $T / I$ procedure and all saw different counselors for our interpretive interviews. Although we all felt some anxiety before the interviews, which may have been heightened because of our investment in the project, we all concluded that it was a very reinforcing experience. One of the authors had her test results related directly to her professional role as a social worker. One author perceived the experience as an interchange between professionals. The other author felt reconfirmed in her identity as a thinking, feeling person. Awareness of the counseling process and exposure to new techniques was a valuable learning experience.

Test results and the interview both played an important role for us. The test findings generated in-depth discussion of those areas of greatest concern for each of us. Personal confirmation was a product both of our test profiles and the interpersonal exchange. 